\title{
Uniformity of thickness of metal sheets by patchwork blanks: potential of adhesive bonding
}

\author{
Gillo Giuliano, Gianluca Parodo, Luca Sorrentino \\ Department of Civil and Mechanical Engineering, University of Cassino and Southern Lazio, Cassino (FR), Italy \\ giuliano@unicas.it, bttps://orcid.org/0000-0003-0018-0438 \\ gianluca.parodo@unicas.it, bttp:/ /orcid.org/0000-0001-7443-6518 \\ sorrentino@unicas.it,bttp://orcid.org/0000-0002-5278-7357
}

\begin{abstract}
The sheet metal forming operations generally involve the production of parts characterized by a non-uniform thickness distribution. However, in some cases, a product characterized by a distribution of thicknesses that is as uniform as possible may be desirable. This result can be obtained by using multiphase processes or by subtraction or addition of material from the blank. In this work, which deals with the method for adding material, an innovative methodology has been proposed as an alternative to the welding process. Specifically, the methodology is based on the bonding of a patch (before the deformation process), on the base plate with a constant thickness, in the area that most suffers from the thinning caused by the forming process. In this way, it was possible to influence the deformation of the patchwork blank and its thicknesses distribution. Through finite element analysis, it was possible to study the formability of a patchwork blank by varying the thickness and size of the patch, in order to produce an axially symmetric component by stretching through a hemispherical punch. Preliminary experimental tests demonstrated the reliability of the bonding and the potential of this method to uniform the final thickness of the sheet.
\end{abstract}

KEYWORDS. AA6060 aluminum alloy; Forming process; Finite element method; Formability limit curve; Adhesive bonding.

\section{open ACcess}

Citation: Giuliano, G, Parodo, G., Sorentino, L., Uniformity of thickness of metal sheets by patchwork blanks: potential of adhesive bonding, Frattura ed Integrità Strutturale, 53 (2020) $166-176$.

Received: 02.03.2020

Accepted: 05.05 .2020

Published: 01.07 .2020

Copyright: (C) 2020 This is an open access article under the terms of the CC-BY 4.0, which permits unrestricted use, distribution, and reproduction in any medium, provided the original author and source are credited.

\section{INTRODUCTION}

$\mathrm{T}$ o meet the growing needs of the automotive industry in terms of safety and comfort, the weight of cars has continuously increased over time. This is due both to the increase in the overall dimensions of the car and to the introduction of various electrical and electronic components [1]. 
The weight of the car results into higher fuel consumption, which leads to an increase in the cost per kilometer as well as an increase in pollution. Therefore, in order to deal with the increased weight of the cars due to the additional components, an attempt was made to reduce the weight of the body.

Generally, sheet metal forming processes are used for the production of automotive parts [2]. Often, the sheet is made of aluminum alloy due to the high strength-to-weight ratio and the high corrosion resistance presented by these materials [3,4]. In addition, reinforced sheets are used where greater strength and stiffness is required [1].

In some cases, a different distribution of the thicknesses of the product obtained by forming may be necessary. This result can be achieved using multiphase processes by subtraction or addition of material from the initial semi-finished product. In $[5,6]$, multi-phase hot forming processes were analyzed to produce components in aluminum alloy (AA2017) and $\mathrm{Pb}-\mathrm{Sn}$ alloy. The subtraction processes of material from a semi-finished product are in developments by the authors.

Tailored blanks are blanks characterized by a local variation of the thickness of the sheet, by a local variation of the material, or by a local variation of the properties of the material. Tailored blanks can be divided into:

- Tailor welded blanks;

- Tailor rolled blanks;

- Tailor heat-treated blanks;

- Patchwork blanks.

Tailor welded blanks are obtained by welding two or more sheets of different thickness in butt joint configuration [7,8]. Welded sheets can be characterized by different thicknesses, coatings, and mechanical properties. The joining of the parts takes place by laser welding or mash seam welding [9]. The use of mash seam welding requires less precision in cutting the sheet metal and allows reaching high welding speeds [10]. On the contrary, laser welding produces a narrow weld seam reducing the heat-affected zone. Laser welding allows reducing the weight of the welded product because it does not require overlapping of the material. In addition, curved welding lines can be made [7]. When non-weldable materials (such as aluminum) must be welded, friction stir welding is used because it does not require the melting of the material [11,12]. In [13], the possibility of reducing the body weight of the car by $25 \%$ was shown by using tailor welded blanks in high strength steel. The main disadvantages in the use of tailor-welded blanks are due to the complexity and high investment costs for carrying out the welding processes [14].

Tailor rolled blanks [15] present a continuous transition between the thickest and thinnest part of the sheet. This produces a more homogeneous distribution of stress, which does not alter the material formability. However, production costs are high, as they require elaborate lamination processes. In [16,17], the optimal process parameters for adopting tailor rolled blanks in the automotive industry were examined.

The goal of tailor heat-treated blanks is to increase the formability of the products, in particular for those materials (highstrength steels, aluminum alloys) that have a limited formability [18]. The mechanical properties are locally modified in order to optimize the subsequent forming operation [19].

The preparation of the patchwork blank partially allows reinforcing a base sheet by using patches [20]. This is done before subjecting the patchwork blank to a forming process [21-23]. For the coupling between the sheet base and the patch, spot welding, laser welding and adhesive bonding can be employed [21]. The preparation of patchwork by spot welding has already been used for the automotive industry [24]. The connection between the parts, using welding techniques, is an automatable operation as opposed to the connection by means of adhesive that requires a preparation of the surfaces to be bonded [25]. Patchwork obtained by bonding technique is still under development.

This work deals with a method by addition of material; in particular an innovative methodology has been proposed as an alternative to the welding process using patches. The methodology is based on the bonding of a patch on a constant thickness base sheet (before the deformation process), in the area that suffers more for the thinning caused by the forming process. Preliminary tests were carried out to highlight the reliability and potential of bonded patchwork blanks, then the influence of the patch types and dimensions on the patchwork blank thickness was numerically analyzed. The numerical model, based on FEM analyses, allowed to identify the most appropriate geometric dimensions of the patch to perform the forming process.

\section{MATERIALS AND METHODS}

$\mathrm{I}$

$\mathrm{n}$ this paragraph, the methods for manufacturing the bonded patchwork blanks and realizing the experimental tests are shown first; therefore, the methods adopted to investigate numerically the formability of the patchwork blank are illustrated. 


\section{Experimental activity}

The process consists in stretching, by means of a hemispherical punch, a sheet positioned on a circular die and constrained, using a blank holder, to deform without sliding inside the die. The forming operations for manufacturing the patchwork blanks were carried out using five rectangular sheet samples $(220 \times 220 \mathrm{~mm}$ ) with a thickness of $1 \mathrm{~mm}$ (Fig. 1). The adopted patches have a circular shape with a radius of $30 \mathrm{~mm}$ and a thickness of $0.1 \mathrm{~mm}$. They were obtained from the base sheet following a rolling process. Subsequently, the patches were bonded on the base sheet. In a first phase, the surfaces of the sheet and the patch to be bended were subjected to a manual sanding treatment with a P100 abrasive paper to improve wettability. Subsequently, in order to remove any possible contaminants, the sheets were subjected to degreasing treatment with acetone. The adhesive used for this activity was the Loctite EA 9309.3NA. It was a two-component paste adhesive, which cured at room temperature in five days [30]. The mechanical properties of the adhesive in the cured state are shown in Tab. 1 [31].

\begin{tabular}{cc}
\hline Properties & Value \\
Tensile Strength & $32.2 \mathrm{MPa}$ \\
Tensile Modulus & $2303 \mathrm{MPa}$ \\
Shear Modulus & $841 \mathrm{MPa}$ \\
Poisson Ratio & 0.36 \\
Elongation at break & $10 \%$ \\
\hline
\end{tabular}

Table 1: Mechanical properties of EA 9309.3NA adhesive.

After five days the adhesive completed the polymerization, therefore it was possible to test the sheets with the bonded patches. In conclusion, five base sheet specimens and five patchwork blanks specimens were produced.

The stretching process of the metal sheets was carried out using the machine present at the Laboratory of Technology and Manufacturing System of the University of Cassino and Southern Lazio, and proposed in [26]. The sheet was blocked between the die and the blank holder in circumferential direction and, therefore, subjected to the action of a hemispherical punch with a radius of $60 \mathrm{~mm}$.

The force-stroke curves of punch were obtained by interpreting the data from a load cell on the forming machine. Details relating to the experimental equipment are reported in [26,32]. For the tests related to the patchwork blanks, a preliminary test of forming was carried out to estimate the punch stroke at failure. In this way, it has been possible to stop the patchwork blank forming tests before the failure for evaluate their thickness distribution. The measurements of the deformed patchwork blanks thicknesses were carried out using the non-contact measurements system FARO Laser ScanArm platinum 6, characterized by an accuracy of $\pm 35 \mu \mathrm{m}$. After the thickness measurements, the tests were continued until failure. The stretching process was carried out in the absence of lubrication. It is known that friction affects the strain path and therefore indirectly on the formability limits of the sheet material. In [32,33], the influence of friction on the Erichsen test results was demonstrated both by using aluminum alloy sheets (AA2017 and AA5083) and steel sheets (DC05). To evaluate the mechanical properties of the material (base sheet and patchwork) it was necessary to perform tensile tests using a Galdabini Sun 10 tensile machine. In this regard, five tensile specimens obtained from the base sheet and five tensile specimens with a bonded patch of $0.1 \mathrm{~mm}$ thickness were manufactured. The tensile tests were carried out according to the standard UNI EN 10002-1:2004.

\section{Numerical activity}

The commercial code of the MSC.Marc based on the finite element method (FEM) was used to simulate the hemisphericalpunch stretch forming process. The numerical simulation considered the tools as rigid bodies while only the sheet was considered deformable. The sheet was discretized into finite elements using axisymmetric elements instead of threedimensional shell elements. In a previous work [26], it has been shown that the type of the used elements does not influence the results. The blank holder, which avoids the sliding of the sheet inside the die, was simulated by fixing the movement of the sheet nodes in the area where the blank holder was present. Furthermore, the displacements of the sheet nodes on the symmetry axis have also been blocked, in order to satisfy the axial symmetry condition. 
The chemical composition by weight of the aluminum alloy used (AA6060) is shown in Tab. 2.

\begin{tabular}{cc}
\hline Elements & Percentage \\
$\mathrm{Si}$ & 0.6 \\
$\mathrm{Fe}$ & 0.3 \\
$\mathrm{Mn}$ & 0.1 \\
$\mathrm{Mg}$ & 0.6 \\
$\mathrm{Cu}$ & 0.1 \\
$\mathrm{Zn}$ & 0.15 \\
$\mathrm{Cr}$ & 0.05 \\
$\mathrm{Ti}$ & 0.1 \\
$\mathrm{Al}$ & rest \\
\hline
\end{tabular}

Table 2: Chemical composition by weight of AA 6060.

The mechanical properties of the base sheet material were determined by tensile tests conducted on specimens with a thickness of $1 \mathrm{~mm}$. The mechanical properties of the material and the methods used for the tests are reported in [26]. The material followed a hardening law of the power type (Hollomon or power law) characterized by a strength coefficient, $\mathrm{K}$, and a strain hardening exponent index, $\mathrm{n}$, and was of the type:

$$
\sigma=K \varepsilon^{n}
$$

where $\sigma$ and $\varepsilon$ represented respectively the equivalent stress and the equivalent strain.

The area where the patch was present has been modelled as an equivalent material, whose mechanical properties have been obtained through specific technological tests, precisely tensile tests of specimens with bonded patch. The parameters for the modelling of the mechanical response of both the base sheet and the patchwork blank were therefore obtained. In the numerical simulations, the patch and the underlying base sheet were represented by elements that were characterized by material parameters $(K$ and $n)$ different from the only base sheet.

Friction between the sheet and the tools was simulated using the modified Coulomb friction model [27], which is characterized by a relation between tangent and normal force of the type:

$$
f_{t}=\mu f_{n}\left(\frac{2}{\pi}\right) \operatorname{arctg}\left(\frac{v_{r}}{R_{s v}}\right)
$$

In Eq.(2), $\mu$ represents the friction coefficient, $v_{r}$ the relative sliding speed and $R_{s v}$ the speed below which $f_{t}=0$.

During FEM analyses, it was possible to assess the formability limit parameter (FLP) [26]. It represents the ratio between the maximum deformation reached in a sheet metal node and the maximum limit deformation coming from a forming limit diagram (FLD). The FLD diagram represents a boundary line between safe and unsafe areas of deformability of the material. In this work, this boundary line was characterized by the boundary conditions introduced by Hill [28] and Swift [29]. Instability in the material occurred when the FLP parameter reaches a unit value in a node of the sheet.

The validation of the model for the forming simulations of only the base sheet was made in another work of the authors [26]. For the case of the patchwork blanks forming simulations, the model was validated by comparison of thickness trends between experimental and numerical results related to a patch with a radius of $30 \mathrm{~mm}$ and a constant thickness of $0.1 \mathrm{~mm}$. For the numerical analysis, three values friction coefficient has been considered $(\mu=0,0.1$ and 0.2$)$.

Further, an analysis of the principal factor of influence were carried out through FEM simulations. Specifically, the effect of patches with different radii and thicknesses was numerically investigated, as the influence of the friction coefficient. 
As stated before, the hemispherical-punch stretch forming process of the base sheet alone was simulated in three friction conditions: $\mu=0,0.1$ and 0.2 . In the same friction conditions, the stretching process was simulated using patchwork blanks. The patchwork blank was characterized by a circular patch with constant $(0.1 \mathrm{~mm}, 0.2 \mathrm{~mm}, 0.3 \mathrm{~mm}, 0.5 \mathrm{~mm}, 0.7 \mathrm{~mm})$ and variable (from 0 to $0.1 \mathrm{~mm}$ ) thickness profile. The radius of the considered patches for the numerical analysis were equal to $10 \mathrm{~mm}$ and $30 \mathrm{~mm}$. To clarify all the conditions, a plan of the numerical activity with all the analyzed factors is reported in Tab. 3. Furthermore, a schematic representation of the two types of patch adopted in this work was shown in Fig. 2.

\begin{tabular}{ccc}
\hline Factors & \# Level & Levels \\
Friction condition $(\mu)$ & 3 & $0 / 0.1 / 0.2$ \\
Patch thickness $[\mathrm{mm}]$ & 6 & Constant $(0.1 / 0.2 / 0.3 / 0.5 / 0.7)$ \\
Latch radius $[\mathrm{mm}]$ & 2 & $10 / 30$ \\
\end{tabular}

Table 3: Plan of numerical tests.

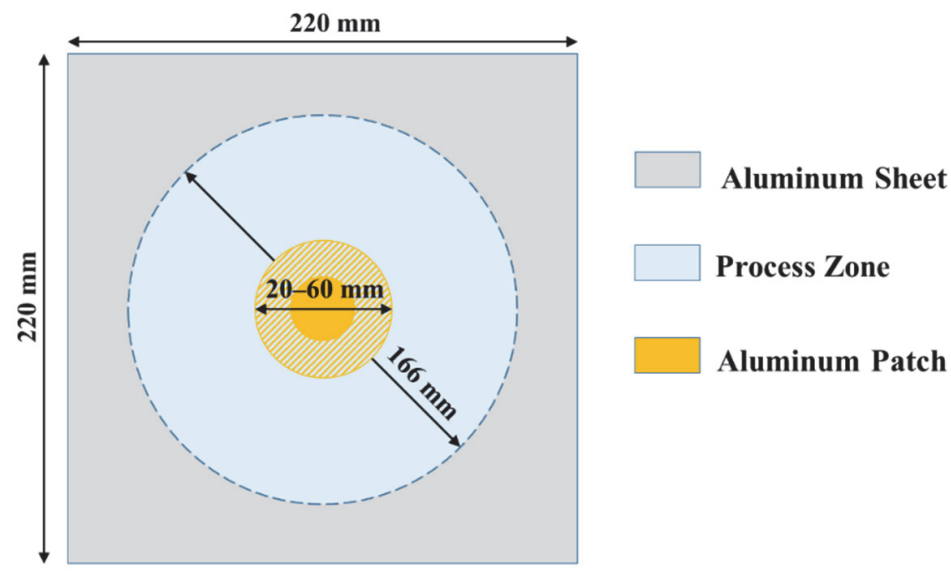

Figure 1: Dimensions related to the sheet samples, the process zone and the patches.

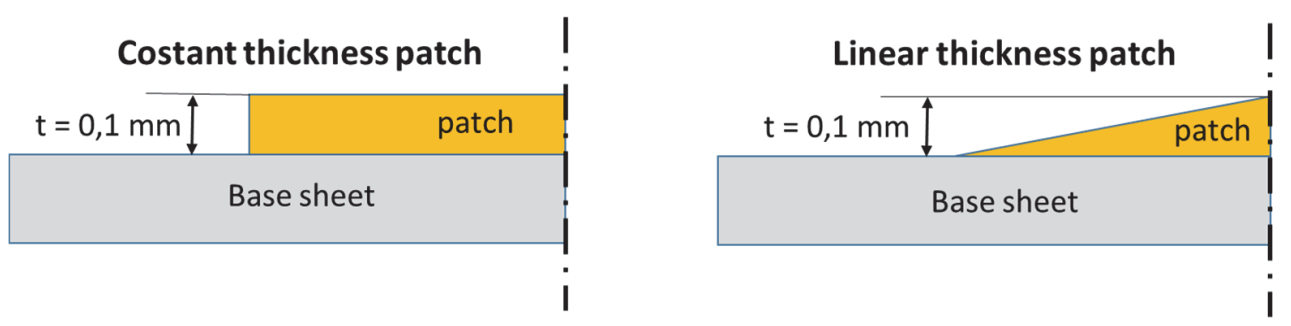

Figure 2: Schematic representation of the two types of patch adopted in this work.

\section{RESULTS AND DISCUSSION}

$\mathrm{T}$

he experimental activity allowed verifying the tightness of the adhesive adopted to connect the patch to the base sheet. The patches were characterized by a thickness of $0.1 \mathrm{~mm}$ and a radius of $30 \mathrm{~mm}$; for this test condition, five replications were made. A preliminary test of forming was carried out to estimate the punch stroke at failure, so the 
subsequently tests were stopped before the failure for evaluate the thickness distribution of the patchwork. The failure appeared with a punch stroke of $18 \mathrm{~mm}$, so all the experimental tests were stopped with a punch stroke of $15 \mathrm{~mm}$. In this way, it was possible to compare the experimental thicknesses distribution with the numerical one. Then the tests were continued until failure. The results of the experimental forming tests at failure are reported in Tab. 4.

\begin{tabular}{ccc}
\hline Specimen type & Base sheet & Patchwork blank \\
Average failure load [N] & 13882.3 & 7954.1 \\
St. Dev. [N] & 777.4 & 720.6 \\
cv & $5.6 \%$ & $9.1 \%$ \\
Average failure stroke [mm] & & \\
St. Dev. [mm] & 29.6 & 18.2 \\
cv & 2.3 & 1.3 \\
\hline
\end{tabular}

Table 4: Experimental results of forming tests for base sheets and patchwork blanks.

Fig. 3 shows, for comparison, the average load-stroke response of the punch recorded during the test both using the patchwork blank and using only the base sheet. This comparison shows that failures (using a patchwork blank) were obtained for a stroke of the punch lower than that achievable in the stretching process of the base plate only. The minor formability of the patchwork is due to the stiffening produced by the operation of bonding the adhesive on the base sheet. This lower formability of the material is however balanced by the possibility of influence the distribution of thicknesses obtainable before reaching the failure conditions. Fig. 4 shows the patchwork deformed at break: the failure occurred in the region of the base plate outside the patch. In addition, the adhesive showed a strong seal, without detaching from the base plate, despite the achievement of high loads (about $8000 \mathrm{~N}$ ). In fact, the aim of this work consisted to evaluate the potentiality of using bonded patch for influence the distribution of thickness and without the debonding of the patch from the base sheet. Obviously in the case of application of this methodology for a real case of study, the deformation must take place before the failure of the component; in fact, the ultimate goal is to obtain the desired deformation with a constant thickness.

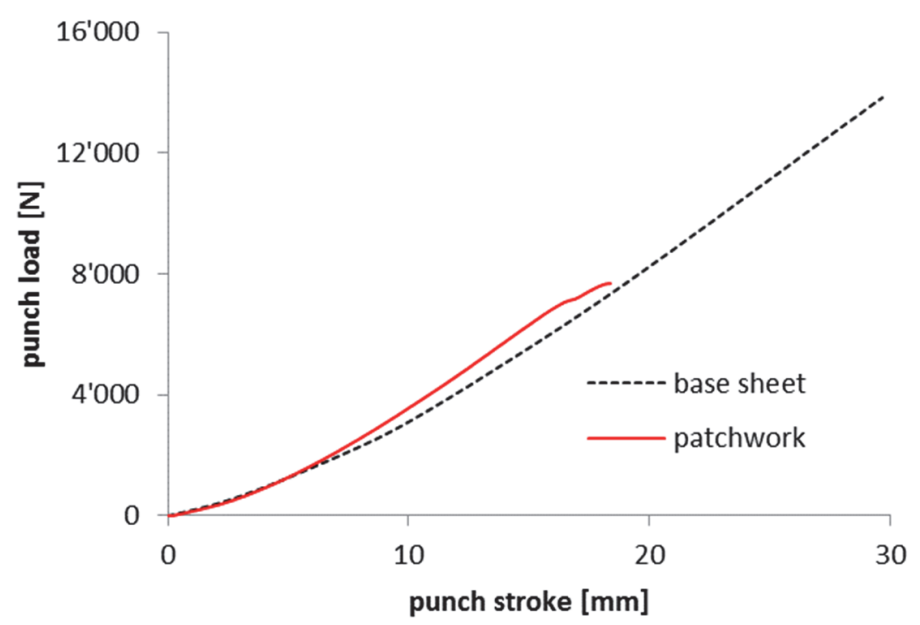

Figure 3: Experimental average force-stroke curves of the punch for base sheets and patchwork blanks characterized by a circular patch of $0.1 \mathrm{~mm}$ thickness and $30 \mathrm{~mm}$ radius.

As stated in the previous paragraph, in the numerical simulations, the patch and the underlying base sheet were represented by elements that were characterized as equivalent material using material parameters (specifically $\mathrm{K}$ and $\mathrm{n}$ ) different from 
the only base sheet. The values obtained from technological tensile tests for patchwork blanks were $\mathrm{K}=128 \mathrm{MPa}$, and $\mathrm{n}=0.08$, while the values obtained for specimens without the bonded patch were $\mathrm{K}=135 \mathrm{MPa}$ and $\mathrm{n}=0.12$.

To validate the numerical model, it was necessary to compare the distribution of the thicknesses obtained by FEM and that measured experimentally at a predetermined stroke of the punch of $15 \mathrm{~mm}$. This comparison, performed between the results of the FEM simulations with a punch stroke of $15 \mathrm{~mm}$ in different friction conditions $(\mu=0,0.1$ and 0.2$)$ and the results of the experimental tests, as shown in Fig. 5. Considering the experimental variation of the results related to the thickness measurements of at least of $3 \%$, it is possible to state that the numerical results showed a good correspondence. In fact, the maximum variation in the FEM thicknesses, compared to the average values experimentally measured, was about $5 \%$ in the case of $\mu=0,3 \%$ in the case of $\mu=0.1$ and $2 \%$ in the case of $\mu=0.2$.

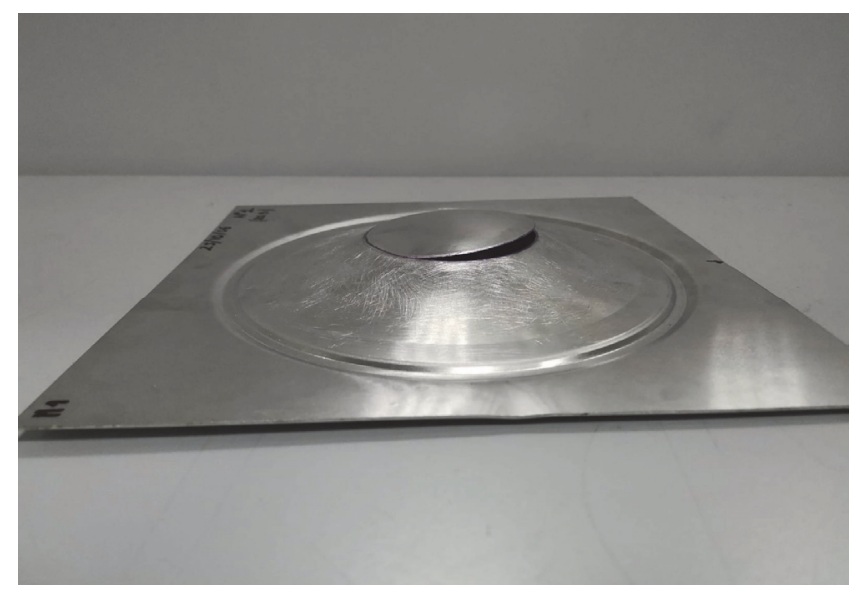

Figure 4: Photo of a bonded patchwork blank sample deformed at failure.

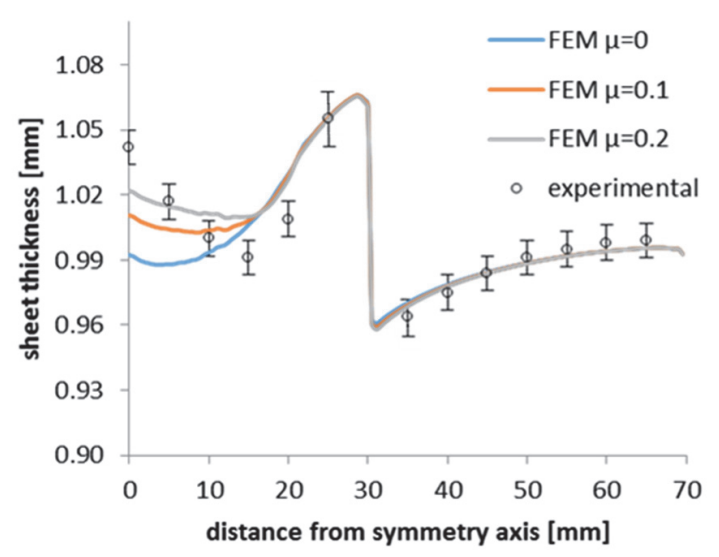

Figure 5: Numerical-experimental comparison of the distribution of the thicknesses after a stroke of the punch of $15 \mathrm{~mm}$ (patch radius equal to $30 \mathrm{~mm})$.

After the validation of the model, the numerical analyses descripted in the previous paragraph have been carried out. In Fig. 6a, some stages of the stretching process were showed, with a particular for observe the mesh adopted for the base sheet. However, the thickness trend until the limit condition was not appreciable from a visual analysis of the mesh. Furthermore, the patch with a thickness of $0.1 \mathrm{~mm}$ appeared very thin for a visual inspection (Fig. 6b).

Fig. 7 shows the stroke of the punch reached at the beginning of the instability condition (when FLP $=1$ ) as a function of the thickness of the patch, related to a patch with a radius of $10 \mathrm{~mm}$. The results obtained for the patch with a radius of 30 $\mathrm{mm}$ were quantitatively very similar with the results showed in Fig.7. In fact, results obtained for the patch with a radius of $30 \mathrm{~mm}$ showed an average decrease in the stroke of the punch of about $3 \%$ compared to the results relating to a patch with a radius of $10 \mathrm{~mm}$. The sheet formability (represented by the stroke of the punch corresponding to the condition FLP $=1$ ) increased as the thickness of the patch decreases. The same result can be achieved both by using a constant thickness patch and a linear thickness patch. In addition, the larger was the patch thickness, the more was the influence of the friction 
condition on the sheet formability. In conclusion, it is possible to state that the patch thickness that showed a lower influence on the friction condition and a higher sheet formability was the one with the thickness of $0.1 \mathrm{~mm}$. Once it was ascertained that the condition involving the greatest formability was related to the use of a patch with a thickness equal to $0.1 \mathrm{~mm}$, the comparison between the results obtained for thicknesses of the patches thicker than $0.1 \mathrm{~mm}$ was considered superfluous and, therefore, was not been reported in the work.
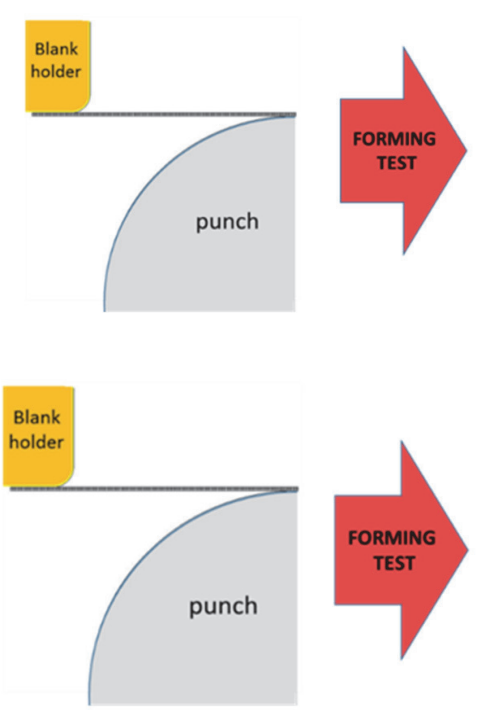

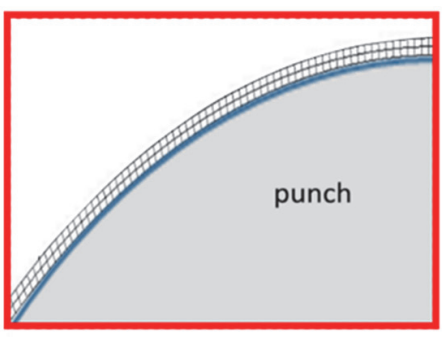

(a)

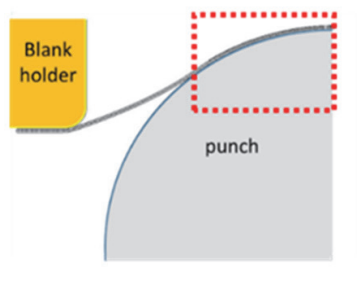

(b)

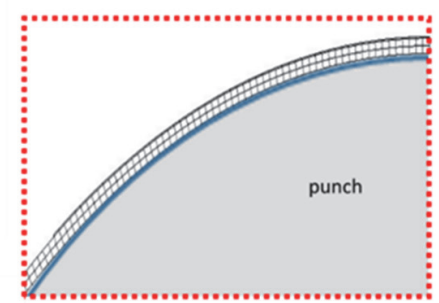

Figure 6: Phases of the FEM simulation of the stretching process with hemispherical punch with particular of the mesh: (a) base sheet only (continuous frame); (b) patchwork blank (thickness equal to $0.1 \mathrm{~mm}$, dotted frame).

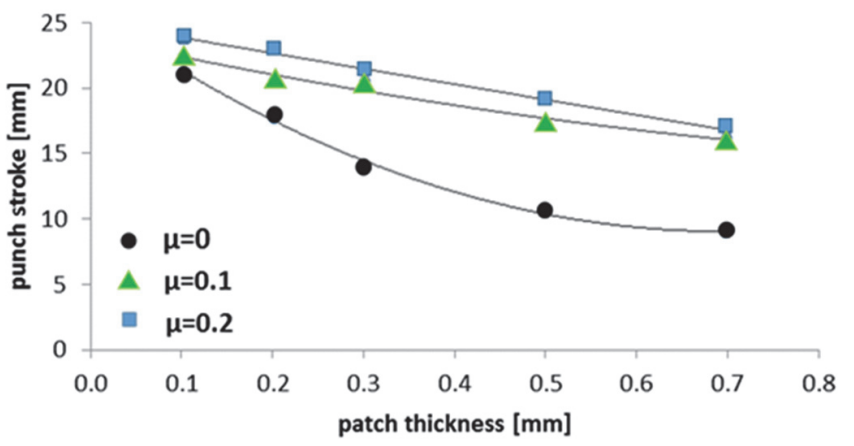

Figure 7: Numerical punch stroke - patch thickness trend for FLP $=1$ (patch radius equal to $10 \mathrm{~mm}$ ).

Fixed a certain stroke of the punch, Fig. 8a shows the distribution of the thicknesses achieved using a $0.1 \mathrm{~mm}$ constant thickness patch patchwork with a patch radius of $10 \mathrm{~mm}$ and $30 \mathrm{~mm}$ and a for the only base sheet. It is possible to state that the most uniform distribution of the thicknesses was determined for a linear thickness patch with a radius of $30 \mathrm{~mm}$ in condition of perfect lubrications. Patches with constant thickness showed a uniform trend until the transition region between the patch and the base sheet, where a drop in thickness has been observed numerically. However, this drop appeared of the same intensity independently from the friction conditions. Probably the adoption of a tapered patch can make the uniform of thickness of the deformed patchwork blanks more consistent. In fact, linear thickness patch showed a more uniform distribution of thicknesses, in particular in case of perfect lubrication. However, in case of linear thickness patch, the dimension of the patch has more strongly influenced the uniformity of the thickness. In conclusion, it is possible 
to state that, among all the patches investigated, the linear patch with a radius of $30 \mathrm{~mm}$ it was the one that guaranteed the optimal distribution of the thicknesses
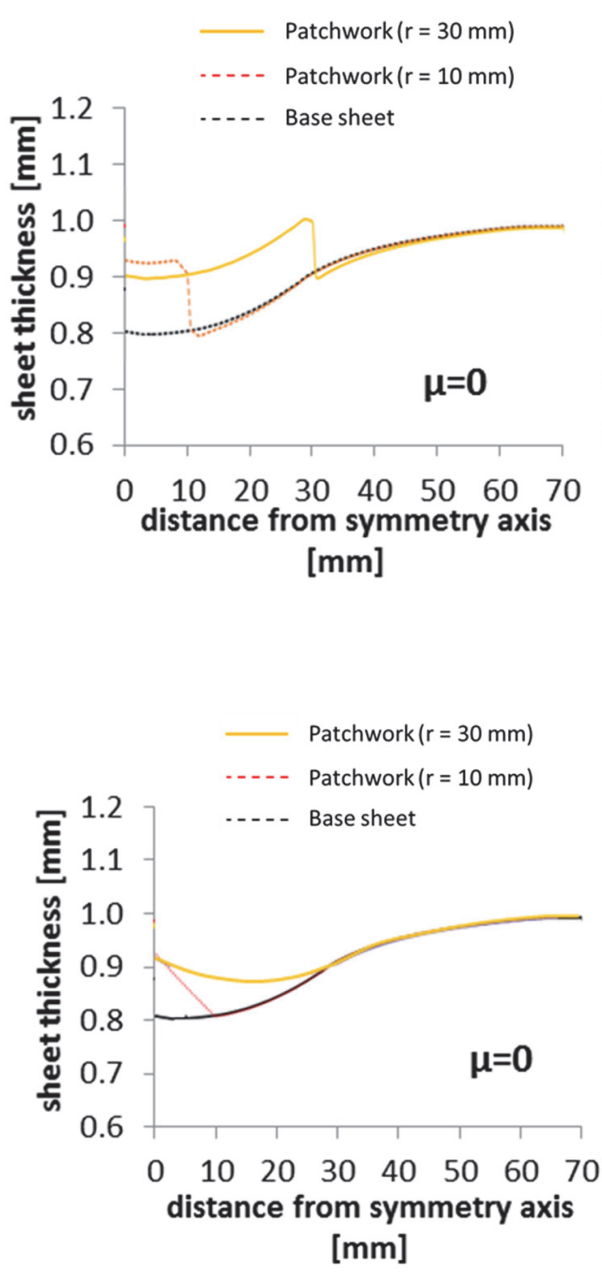

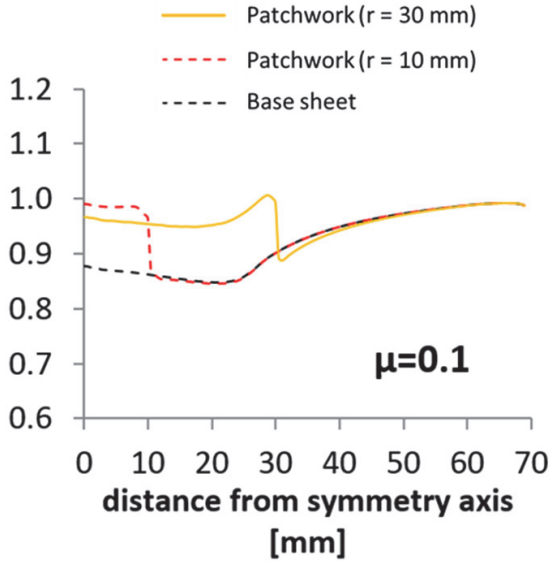

(a)

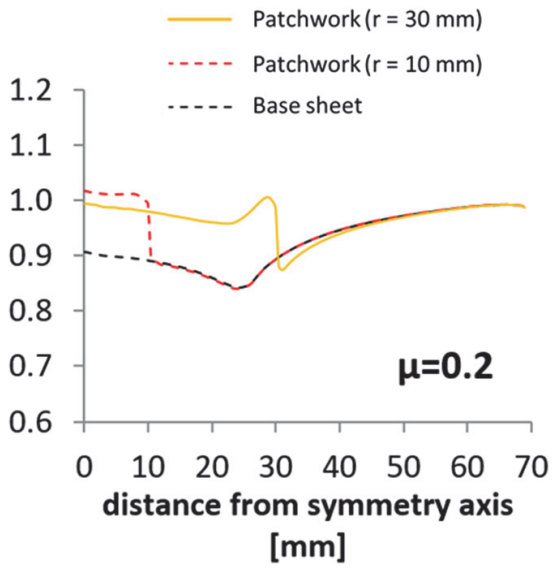

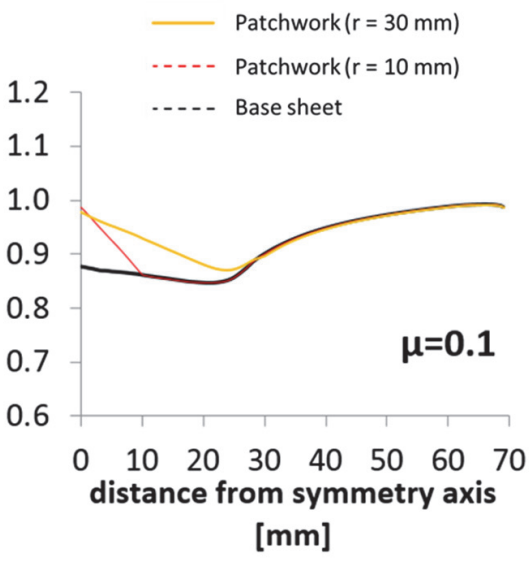

(b)

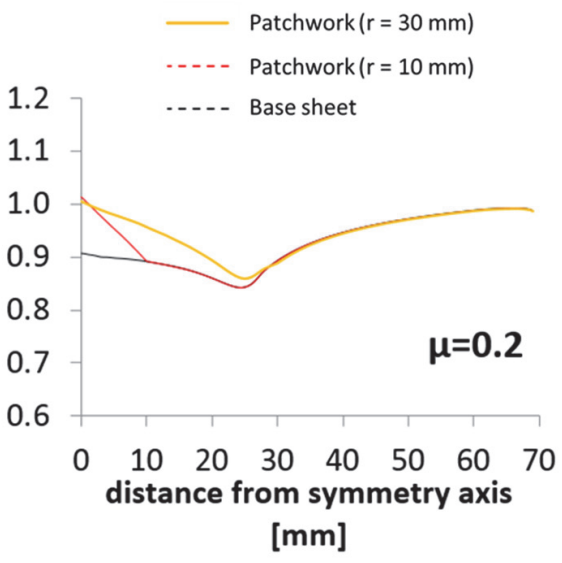

Figure 8: Numerical distribution of the thicknesses between base sheets and patchwork blanks with radius of $10 \mathrm{~mm}$ and $30 \mathrm{~mm}$ : (a) constant thickness patch of $0.1 \mathrm{~mm}$; (b) linear thickness patch.

\section{CONCLUSIONS}

he aim of this work was to show the potential of using a bonded patchwork blank by means of a bonding process to obtain a product characterized by a distribution of thicknesses that is as uniform as possible. Experimental tests showed the capability of bonded patch of influencing the thickness distributions during forming process, specifically to stretching process with a hemispherical punch. Subsequently, a FEM model was validated to investigate the effects of patch dimensions on the distribution of thickness in the patchwork blanks. In fact, through finite element analysis, it was possible to define the appropriate geometric characteristics of a patchwork blanks. Therefore, in the case examined it was possible to establish the most appropriate thickness and radius values of the patch to produce a component of simple geometry. Results showed a more uniform distribution of thickness for linear patch with a radius of $30 \mathrm{~mm}$, while constant thickness patch showed a drop in thickness near the edges of the patch. Further research developments will include the experimental investigations of the efficacy of linear thickness patches in case of more complex geometries and adopting other sheet materials. 


\section{REFERENCES}

[1] Merklein, M., Johannes, M., Lechner, M., Kuppert, A. (2014). A review on tailored blanks - Production, applications and evaluation, J. Mater. Process. Technol., 214(2), pp. 151-164, DOI: 10.1016/j.jmatprotec.2013.08.015.

[2] Rong, H., Hu, P., Ying, L., Hou, W., Zhang, J. (2019). Thermal forming limit diagram (TFLD) of AA7075 aluminum alloy based on a modified continuum damage model: Experimental and theoretical investigations, Int. J. Mech. Sci., 156, pp. 59-73, DOI: 10.1016/j.ijmecsci.2019.03.027.

[3] Tisza, M., Czinege, I. (2018). Comparative study of the application of steels and aluminium in lightweight production of automotive parts, Int. J. Light. Mater. Manuf., 1(4), pp. 229-238, DOI: 10.1016/j.ijlmm.2018.09.001.

[4] Hirsch, J. (2014). Recent development in aluminium for automotive applications, Trans. Nonferrous Met. Soc. China, 24(7), pp. 1995-2002, DOI: 10.1016/S1003-6326(14)63305-7.

[5] Giuliano, G., Corrado, A., Polini, W. (2018). Influence of multiphase forming approach on the thickness uniformity of components from superplastic PbSn60 alloy, Manuf. Lett., 18, pp. 16-19, DOI: 10.1016/j.mfglet.2018.09.004.

[6] Giuliano, G. (2019). Multiphase gas blow forming of AA2017, J. Test. Eval., 47(2), pp. 1236-1243, DOI: 10.1520/JTE20170086.

[7] Zadpoor, A.A. (2007). Mechanics of Tailor Welded Blanks: An Overview, Key Eng. Mater., 344, pp. 373-382, DOI: $10.4028 /$ www.scientific.net/KEM.344.373.

[8] Kinsey, B.L., Wu, X. (2011). Tailor welded blanks for advanced manufacturing.

[9] Saunders, F.I., Wagoner, R.H. (1996). Forming of tailor-welded blanks, Metall. Mater. Trans. A Phys. Metall. Mater. Sci., 27(9), pp. 2605-2616, DOI: 10.1007/BF02652354.

[10] Miyazaki, Y., Sakiyama, T., Kodama, S. (2007). Welding techniques for tailored blanks, Nippon Steel Tech. Rep., (95), pp. 46-52.

[11] Buffa, G., Fratini, L., Merklein, M., Staud, D. (2007). Investigations on the mechanical properties and formability of friction stir welded tailored blanks, 344 .

[12] Mishra, R.S., Ma, Z.Y. (2005). Friction stir welding and processing, Mater. Sci. Eng. R Reports, 50(1-2), pp. 1-78, DOI: 10.1016/j.mser.2005.07.001.

[13] ULSAB. (2013). Programme Report.

[14] Mohrbacher, H. (2001).A critical review of laser welding technology for mass production of tailored blanks. Proceedings of the 9th International Conference on Sheet Metal, Leuven, Belgium, pp. 305-12.

[15] Kopp, R., Wiedner, C., Meyer, A. (2005). Flexibly rolled sheet metal and its use in sheet metal forming, 6-8.

[16] Klinke, N., Schumacher, A. (2016).Finding the best thickness run parameterization for optimization of Tailor Rolled Blanks. LS-DYNA Forum 2016.

[17] Han, S., Hwang, T., Oh, I., Choi, M., Moon, Y.H. (2018). Manufacturing of tailor-rolled blanks with thickness variations in both the longitudinal and latitudinal directions, J. Mater. Process. Technol., 256, pp. 172-182, DOI: $10.1016 /$ j.jmatprotec.2018.02.013.

[18] Geiger, M., Merklein, M. (2007). Sheet Metal Forming - A New Kind of Forge for the Future, Key Eng. Mater., 344, pp. 9-20, DOI: 10.4028/www.scientific.net/kem.344.9.

[19] Kahrimanidis, A., Lechner, M., Degner, J., Wortberg, D., Merklein, M. (2015). Process design of aluminum tailor heat treated blanks, Materials (Basel)., 8(12), pp. 8524-8538, DOI: 10.3390/ma8125476.

[20] Lamprecht, K., Geiger, M. (2005). Experimental and numerical investigation of the formability of laser welded patchwork blanks, Adv. Mater. Res., 6-8, pp. 689-696, DOI: 10.4028/www.scientific.net/amr.6-8.689.

[21] Streitberger, H.-J., Dossel, K.-F. (2008). Automotive Paints and Coatings, Weinheim, Wiley-VCH.

[22] Lei, C., Xing, Z., Xu, W., Hong, Z., Shan, D. (2017). Hot stamping of patchwork blanks: modelling and experimental investigation, Int. J. Adv. Manuf. Technol., 92(5-8), pp. 2609-2617, DOI: 10.1007/s00170-017-0351-9.

[23] Petitjean, P.-D., Lescart, J.-C., Sener, J.-Y., Delfanne, S. (2001). Patchworks: From design to manufacture | Patchworks: De la conception à l'industrialisation, Rev. Metall. Cah. D’Informations Tech., 98(10), pp. 911-926, DOI: $10.1051 /$ metal:2001138.

[24] Magain, P., Dawance, J., Delfanne, S., Chamont, B., Fournet, A. (1998). The patchwork technique for proper material placement on panels: Industrial application on the new peugeot 206, SAE Tech. Pap., DOI: 10.4271/982402.

[25] Sorrentino, L., Polini, W., Bellini, C., Parodo, G. (2018). Surface treatment of CFRP: influence on single lap joint performances, Int. J. Adhes. Adhes., 85(May), pp. 225-233, DOI: 10.1016/j.ijadhadh.2018.06.008.

[26] Giuliano, G., Bellini, C., Sorrentino, L., Turchetta, S. (2018). Forming process analysis of an AA6060 aluminum vessel, 45, pp. 164-172, DOI: 10.3221/IGF-ESIS.45.14. 
[27] Bellini, C., Giuliano, G., Sorrentino, L. (2019). Friction influence on the AA6060 aluminium alloy formability, Frat. Ed Integrità Strutt., 13(49), pp. 791-799, DOI: 10.3221/IGF-ESIS.49.70.

[28] Hill, R. (1948). A theory of the yielding and plastic flow of anisotropic metals, Proc. R. Soc. London. Ser. A. Math. Phys. Sci., 193(1033), pp. 281-297, DOI: 10.1098/rspa.1948.0045.

[29] Swift, H.W. (1952). Plastic instability under plane stress, J. Mech. Phys. Solids, 1(1), pp. 1-18, DOI: 10.1016/0022-5096(52)90002-1.

[30] Sorrentino, L., Bellini, C., Parodo, G., Turchetta, S. (2019). Increasing of ENF Bonded Joints Performance by Design of Laser Surface Texturing, Key Eng. Mater., 813, pp. 346-351, DOI: 10.4028/www.scientific.net/KEM.813.346.

[31] Sorrentino, L., Marfia, S., Parodo, G., Sacco, E. (2020). Laser treatment surface: An innovative method to increase the adhesive bonding of ENF joints in CFRP, Compos. Struct., 233(February 2020), pp. 111638, DOI: $10.1016 /$ j.compstruct.2019.111638.

[32] Giuliano, G. (2015). Evaluation of the Coulomb friction coefficient in DC05 sheet metal forming, J. Mech. Eng., 61(12), pp. 709-713, DOI: $10.5545 /$ sv-jme.2015.2733.

[33] Giuliano, G., Samani, F. (2013). Effect of lubrication on the Erichsen Test, Appl. Mech. Mater., 365-366, pp. 425-428, DOI: 10.4028/www.scientific.net/AMM.365-366.425. 